\title{
SiMULATION INTERFACE FOR TECHNICAL TRAINING IN DETECTION OF FLAWS
}

\author{
J. L. Pérez, F. Cabiedes, F. Gamboa, A. Viniegra, E. Bernal, J. Ramírez, A. Guerrero \& J. L. Guzmán. \\ Center of Applied Sciences and Technological Development, UNAM \\ E-Mail: pepito@aleph.cinstrum.unam.mx
}

Received: October 21 ${ }^{\text {st }}$, 2001. Accepted: December $3^{d}, 2003$

\begin{abstract}
In this paper we present a computer program with educational purposes, based on the substitution of student's beliefs by formal knowledge via personal experience. This is done through the application of formal knowledge acquired in class, to contextualized tasks in the student's environment that also allows him/her to obtain and consolidate basic information that is not embedded in his/her mind. The program is designed to present a gamelike exercise that allows the student to face conditions similar to those of real life.

RESUMEN

En este trabajo se presenta un programa de computadora con fines educativos, basado en la sustitución de las creencias del estudiante por conocimiento formal vía experiencia personal. Esto, mediante la aplicación del conocimiento formal adquirido en clase a tareas contextualizadas en el medio ambiente del estudiante, lo cual le permite obtener y consolidar información básica no arraigada en su mente. El programa está diseñado para presentar un ejercicio parcialmente lúdico, que le permite enfrentarse a condiciones similares a las de la vida real.
\end{abstract}

KEYWORDS: Student Centered Educational Software; Situated Learning; Simulators and Education.

\section{INTRODUCTION}

The belief is the principle through which students perceive and understand their reality. Actually, this principle governs, in a preponderant way, the manner in which external stimulus impacts on them; call it learning, affection or rejection. Trying to give an explanation about the meaning of the belief will only get us tangled in a discussion that at least is futile. However, we can try to describe it and to determine its influence in the acceptance or rejection of concepts that cohabits in the student.

The belief is a way to know and to represent (at least to explain), the world and the nature of things. In the current theory of knowledge it is assumed that a belief does not require any additional information or prove, neither associates any logical reasoning such as induction or deduction, and of course that it is the less convenient form of knowledge. However, on the other hand, we can grant that the belief is one of the most robust ways people have to structure the knowledge and their representation of the world. Therefore one can assume that the belief is a structural part of the student. Actually we all use to hang up on beliefs, in some cases desperately. 
The origin of the belief can be seen as a combination of two factors: the first one, the student's particular explanation of the events to which he/she has access, and/or are generated for him; the second, the influences of his/her social environment. These ideas are accepted and grasped in such a way, that the explanation of the environment spreads to be constituted in an acceptable reality for the student (the cultural imaginary).

We can divide beliefs in two main groups: those that are absolutely indispensable, and those that are not necessarily required. In some cases, the belief becomes a voluntary act, in a way that a subjective element, such as pleasure or preference, defines, at least partially, which beliefs will become a substantial part of the individual's idiosyncrasy. This way, one can understand that those who want to see ghosts will see them, and those who do not want wouldn't see them. However, we will find cases in which the belief is a piece of knowledge, incrusted in the student from its social environment. We call these induced beliefs, because they are assimilated by students from their environment, and appropriated in such a way, that they become even capable of feeling themselves responsible for them. We believe that it is only in these cases when a student really appropriates an idea as his own.

The educational system assumes that students, through the single act of reasoning, will conclude and accept that this set of basic ideas lacks of foundation, that they should be discarded and replaced with the new concepts that are presented to them in the class room. In our opinion, this mechanism of substitution of ideas only develops in students a defensive strategy that consists in representing, in front of the teacher, the behaviors that they believe appropriate and that guarantees them to obtain a passing mark. This means that students answer in classroom what they believe they have been asked for: the exactly content of the course book or, in the best of cases, what they think the teacher expects as response. However, once the formal interrogation in class has finished, the student discards everything and returns to her/his original beliefs, if at some time she/he has abandoned them.

As a result of this situation, students live in a constant duality, being forced to perform an act of faith in front of the teacher, or the content of a book. Under this paradigm, students are just unable to appropriate the ideas presented to them. This derives in the fact that knowledge, as it is presented to them, has very little relation with their social environment or with their previous experiences. As a result, students replace with memory the reasoning that, otherwise, would allow them to integrate the knowledge that they should accumulate as their studies advance.

A second relevant problem is that scientific knowledge tends to present facts as generalities. This leads teachers to present students with situations completely out of the context of their individual experience. We believe that this distance contributes to produce not only rejection, but also the student's separation, as an individual, from the school discourse. Let us give an example: modern science affirms that Earth rotates around the Sun. However, in the social context it is accepted that it is the Sun the one that rises from east, as if it was the sun the one that is moving. In other words, we all see that the Sun appears on the East, but we are told that it is Earth the one that rotates, and therefore, we are the ones that are advancing towards the sun. This simple example shows how the scientific discourse goes against the common sense of the observer, producing that the duality persists.

From the above mentioned comes off that to substitute a belief, it is required something more than a logically creditable explanation; it requires that this explanation can prove false our original belief, and that it gives us strong evidence to accept that our ideas might be false. In other words, a student must be leaded to question about his/her own principles, before he/she can substitute them with new knowledge, in the same intimately way as the others. In some cases the logic, angular stone of the reason, might be enough; in others, only the exhibition to the direct experiences allows that this substitution can take place, although it does not guarantee it.

Until here, we have exposed two problems that apparently might be treated separatedly: on one hand, the belief, as personal and intimate, as scientifically rejected, and on the other hand, by on one hand, the scientific knowledge as an entity without references in the context of the individual's experience. In both cases the student does not succeeds to integrate the knowledge presented in class by teachers, or in books, to the group of beliefs that helps 
him to represent and understand the world. In other words, students do not co-participate with the ideas, and therefore, they do not assimilate them as something of their own.

As a direct consequence of this appear feelings such as frustration or anxiety, complicating even more the learning process, hindering and avoiding the student to continue receiving a necessarily accumulative knowledge (Algebra as a base to understand Calculus, etc.) The subject does not establish any base to construct more complex structures of knowledge, and therefore he/she moves away from the possibility of understanding their consequences.

In this context, if we can make the student to doubt about his/her beliefs, in favor of new beliefs, sustaining this case in scientific knowledge, we would probably achieve that they became a co-participants of this new knowledge, so they assimilate it as of their own. On the other hand, if we also provide them with situations that can be easily related with their personal experience, we will help the student in the assimilation of the new knowledge, and not only to retain them by heart.

In this sense, we believe that a collection of experiences strongly contextualized, where the student has a roll that allows him/her to participate as a part of the story, its solution and conclusions can be appropiate to facilitate their learning process. Likewise, we believe that a positive feedback, in terms of assigning students tasks that can be successful, that have a direct relation with their everyday experience, or a meaning in their own field of study, converts the subject in a co-participant of the concept, knowledge or idea.

The acceptance of induced concepts can only be corroborated by the subject, and therefore interiorized, through the appropriation of the concepts as a part of its lived experience. That is why we believe that putting into practice the contextualized knowledge, not only reaffirms it, but rather overturns it to the student's direct and personal experience. In this sense, being a witness and co-author of an experience allows the subject to stop believing in what others say to him/her, and to integrate the experience in his/her personal history as of his/her own. Besides, if the subject generates for itself outlying experiences about the task that he/she carries-out, this facilitates him/her to establish a link among what he/she should do, and what gives him/her satisfaction, referred this to the sensation of triumph that is obtained with the job done.

\section{THE WORKSHOP OF Mr. NUTS}

"The workshop of Mr. Nuts" is a software designed to train students in the detection and reparation of failures in pneumatic, hydraulics and refrigeration equipment. The idea of this software arises from the fact that, in general, the didactic equipment of technical high schools do not allow teachers to manipulate the elements so they can simulate some of the most typical failures that a professional must face in his/her working life. This is why we have developed a virtual laboratory, that permits students to be trained in the detection and reparation of failures, applying the theoretical knowledge acquired in class in very concrete cases, selected out from real life problems (such as the doors of a bus that get stuck).

The laboratory consists of:

i) A schematic presentation of a "reference" circuit. This circuit shows students how the circuit is supposed to work. We show the schematic diagram, and not the involved object, because we seek to reinforce the student's ability to read schematic diagrams.

ii) A schematic presentation of the circuit to be repaired. This circuit is where the student can make measurements, observations, replacement of pieces, etc. The reason of why it is a diagram, and not an object is the same that above;

iii) Measurement tools such as gauge, flux-meter, voltmeter and ammeter that allow the student to carryout measurements in the diverse test points of the circuit. The result of these measurements is displayed in a digital screen in the top of the screen. With these tools the student should be able to detect the failure in the circuit.

iv) Actions and parts are a group of replacement pieces and actions that the user can carry out to repair the fault that has been detected. 


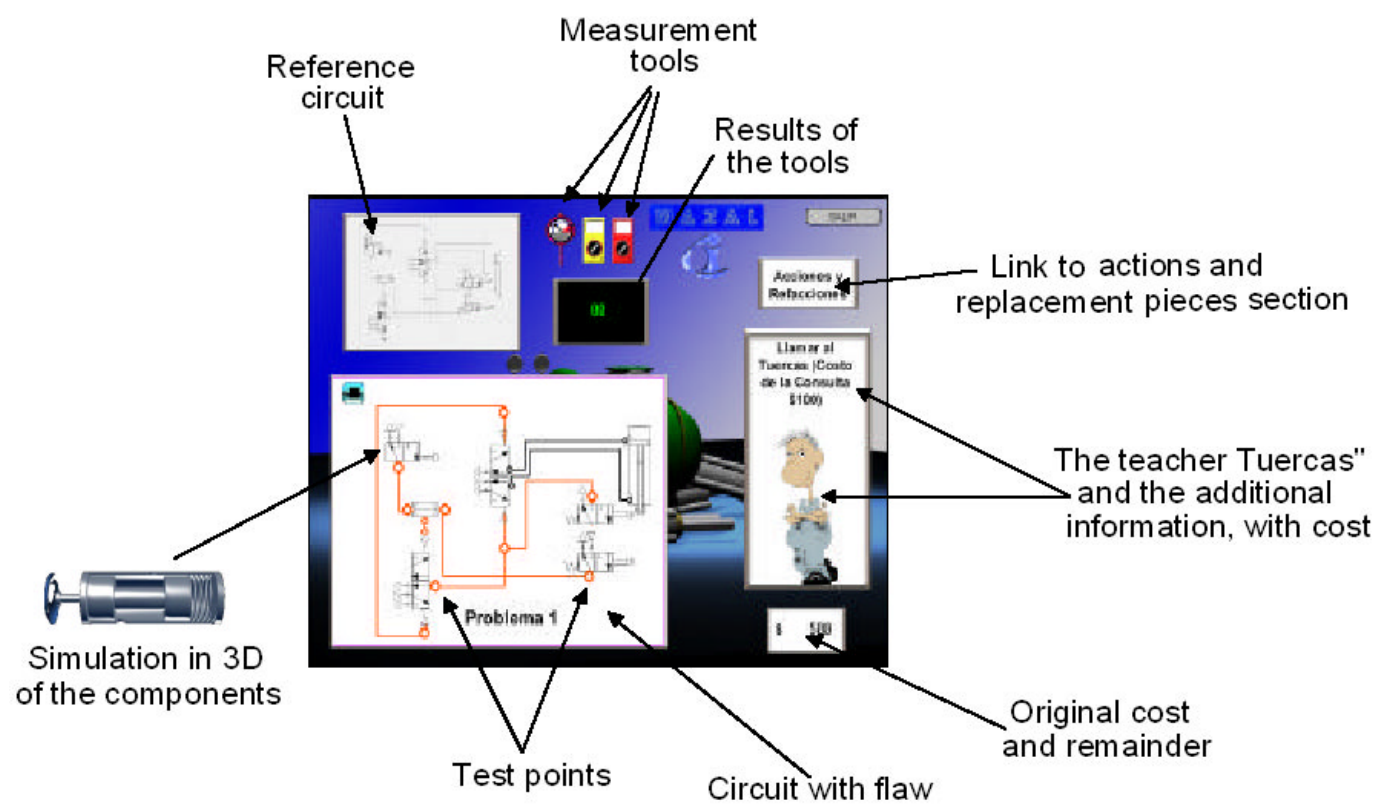

Figure 1. Main screen of the Workshop of Mr. Nuts

The program also includes a courseware that allows students to review and clarify the theoretical concepts and data that are fundamental to understand the practice and to solve it. We are extending these materials, so they include the physical concepts that are involved in the operation of the circuits and equipments presented to the student. In the first version these materials are constructed as windows help hypertexts, but we are considering their development with an interface more likely to the one of the workshop.

In the software, students play the roll of a technician who must attend clients, manage budgets, etc. The program presents a menu that allows the student to choose the practice on which he/she wants to work. However, the same problem can be presented by three different clients, each one of them with different expertise level. The program selects one of the clients randomly, so when a student decides to abandon a practice, the type of information that he/she will obtain the next time will not be the same.

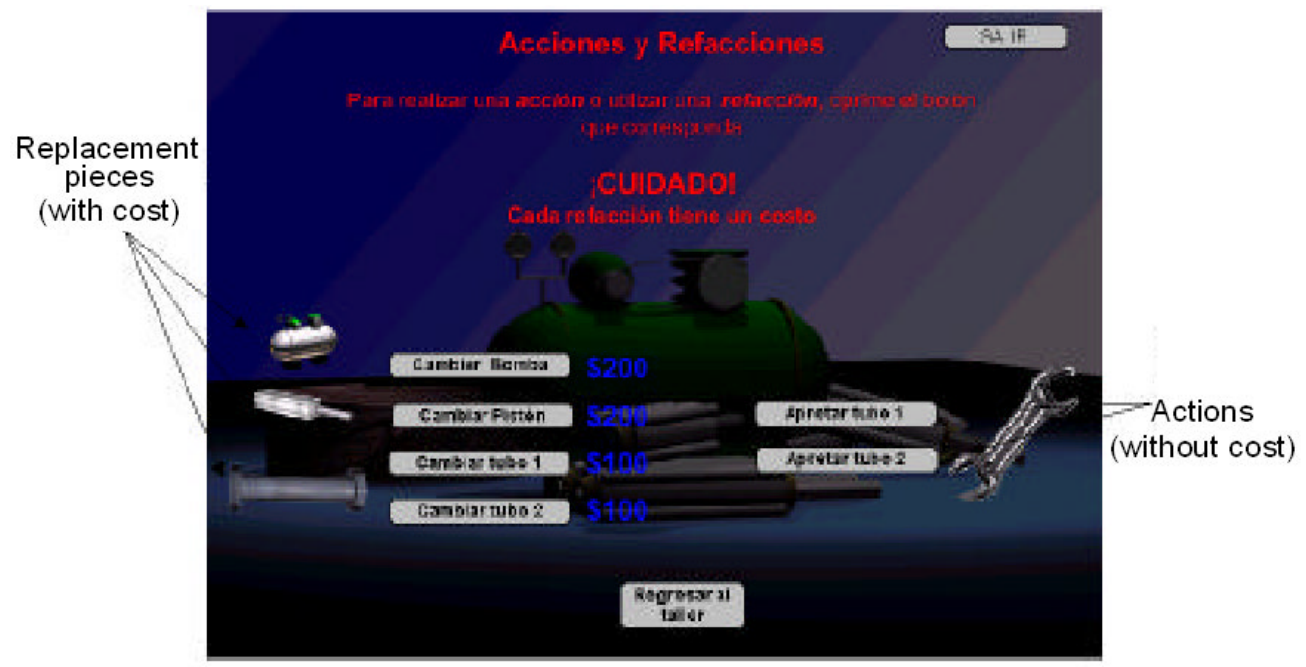

Figure 2. Screen of actions and replacement of the "Workshop of Mr. Nuts" 
The importance of clients resides in the kind of information that each one will provide to the user, and its accuracy: we have programmed clients that have nearly no idea of which the fault is; anothers that can give a better description of the problem, and even the ones that might give contradictory information to the user (see Figure 3). This way, students are presented to some of the problems that they will have to face when a client is requesting their services.

The clients presented in Figure 3 are involved with a first block of practices, where the case of blocked door in a bus is presented. In this first block, the same circuit is presented with three different failures, each one corresponding to three different levels of complexity.

As one can observe, the software follows an approach that might be qualified as joyful. Indeed, the software is designed to be used by students as a game, where the challenge is to repair a specific artifact, keeping the highest possible amount of money; this is to say, to expend a minimum of the saved money in parts and advices from Mr. Nuts.

\begin{tabular}{|c|c|c|}
\hline Name of the client & Illustration & Type of information \\
\hline $\begin{array}{l}\text { Chófiras: } \\
\text { Chauffeur of the bus whose } \\
\text { door requires repair }\end{array}$ & & $\begin{array}{l}\text { Complete, however } \\
\text { confused presentation } \\
\text { when speaking }\end{array}$ \\
\hline $\begin{array}{l}\text { El Güilis. } \\
\text { The chauffeur's assistant. }\end{array}$ & & $\begin{array}{l}\text { Partial and confused. } \\
\text { He presents a description } \\
\text { almost onomatopeyic }\end{array}$ \\
\hline El Lic. & & $\begin{array}{l}\text { Practically null, } \\
\text { this character only } \\
\text { indicates that the } \\
\text { door doesn't work. }\end{array}$ \\
\hline
\end{tabular}

Figure 3. The Clients and their grades of information

The approach also encourages the competition among students, with regard to which has earned more money, allowing at the same time that the professor use this information as an element to evaluate the student's progress.

\section{CONCLUSIONS}

In this paper we have presented an approach that intends to help students in the grasp of formal concepts through the analysis and solution of concrete applied exercises. This approach is known as "situated learning": students are presented to situations that are well known to them, and that therefore can be easily identified, contextualized and accepted. This, as a point of departure to the substitution of beliefs, is an effective way to put in practice the theoretical knowledge acquired in the classroom, working in cases that can be directly referred to the student's everyday personal experience.

The introduction of computational programs with this kind of elements, allow us to see them as games that include (hidden) theoretical books, leading students to extend the knowledge that have no yet being completely assimilated.

The first results obtained with students are encouraging, and make us believe that the presented approach can be a solution for many problems that educational software has encountered, allowing students to make significant advances in their learning; and even more, the experience represents an effective way to make student's become coowner of the created solution, as well as the involved concepts, and promoter of them. 